\title{
Conselho local de saúde: implantação e dificuldades da formação na Estratégia Saúde da Família
}

\section{Local Health Council: formation implementation and difficulties in the Family Health Strategy}

\section{Consejo local de salud: implantación y dificultades para la formación de la Estrategia de Salud Familiar}

\author{
Leilany Dantas Varela \\ Secretaria Municipal de Saúde de Milagres - Milagres (CE) - Brasil
}

Rauana dos Santos Faustino (iD

Universidade Estadual do Ceará - Fortaleza (CE) - Brasil

Consuelo Helena Aires de Freitas (iD

Universidade Estadual do Ceará - Fortaleza (CE) - Brasil

Yana Paula Coêlho Correia Sampaio iD

Faculdade de Medicina Estácio de Juazeiro do Norte - Juazeiro do Norte (CE) - Brasil

Rogério Sampaio de Oliveira (iD

Faculdade de Medicina Estácio de Juazeiro do Norte - Juazeiro do Norte (CE) - Brasil

Antonio Germane Alves Pinto (iD

Universidade Regional do Cariri - Crato (CE) - Brasil

Evanira Rodrigues Maia (iD

Universidade Regional do Cariri - Crato (CE) - Brasil

Maria do Socorro Vieira Lopes (iD

Universidade Regional do Cariri - Crato (CE) - Brasil

\section{RESUMO}

Objetivo: Descrever o processo de implantação do Conselho Local de Saúde, incluindo a formação e as dificuldades enfrentadas, por meio da visão dos conselheiros, com ênfase na participação social no território da Estratégia Saúde da Família. Métodos: Estudo de natureza qualitativa, com abordagem crítico-reflexiva, realizado de fevereiro a julho de 2016 no território de uma equipe da Estratégia Saúde da Família no município de Milagres, Ceará, Brasil, com 22 usuários e trabalhadores de saúde integrantes do Conselho Local de Saúde. A pesquisa ocorreu por meio de técnicas de observação sistemática, levantamento documental, entrevista semiestruturada e grupo focal. Emergiram três categorias: Contextualidades na implantação do Conselho Local de Saúde; Formação do Conselho Local de Saúde frente às situações cotidianas da comunidade: necessidades de saúde, participação e renovação; Dificuldades enfrentadas no processo de organização do Conselho Local de Saúde. Resultados: Os problemas locais foram os motivos para a participação e a mobilização da comunidade na implantação e formação do Conselho Local de Saúde. A organização e o funcionamento do conselho envolveram usuários e equipe de saúde em práticas integradas às demandas e necessidades do território. A participação comunitária, o empoderamento para cidadania e a corresponsabilização solidária das pessoas emergiram no processo de planejamento local das ações de saúde e no enfrentamento coletivo das dificuldades cotidianas. Conclusão: As mudanças ocorridas no território da Estratégia Saúde da Família com a implantação e formação do Conselho Local de Saúde evidenciam a potencialidade desse dispositivo de participação social.

Descritores: Planejamento em Saúde; Planejamento Participativo; Estratégia Saúde da Família; Conselhos de Saúde.

\section{ABSTRACT}

Objective: To describe the process of implementation of the Local Health Council, formation and difficulties faced, through the view of the counselors, with an emphasis on social participation in the territory of the Family Health Strategy. Methods: Study of

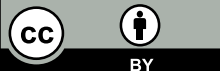


a qualitative nature, with a critical-reflexive approach. Held in the territory of a Family Health Strategy team in the city of Milagres, Ceará, Brazil, with 22 subjects, users and health workers members of the Local Health Council. The survey took place between February and July 2016, through systematic observation techniques, documentary survey and focus group. Data analysis based on hermeneutics and dialectics was chosen. Results: The local problems were the reasons for community participation and mobilization in the implantation and formation of the Local Health Council. The organization and functioning of the council involved users and the health team in practices integrated to the demands and needs of the territory. Community participation, empowerment for citizenship and the joint responsibility of people emerged in the process of local planning of health actions and in the collective confrontation of daily difficulties. Conclusion: The changes that occurred in the Family Health Strategy territory with the implementation and formation of the Local Health Council show the potential of this social participation device. The weaknesses in the council's organization underscore the need for encouragement, support and support at the base of the Unified Health System.

Descriptors: Health Planning; Participative Planning; Family Health Strategy; Health Councils.

\section{RESUMEN}

Objetivo: Describir el proceso de implantación del Consejo Local de Salud incluyendo la formación y las dificultades afrontadas a través de la opinión de los consejeros con énfasis en la participación social del territorio de la Estrategia de Salud Familiar. Métodos: Estudio de naturaleza cualitativa de abordaje crítico-reflexivo realizado entre febrero y julio de 2016 en el territorio de un equipo de la Estrategia de Salud Familiar del municipio de Milagres, Ceará, Brasil, con 22 usuarios y trabajadores sanitarios del Consejo Local de Salud. La investigación se dio a través de técnicas de observación sistemática, recogida de documentos, entrevista semiestructurada y grupo focal de los cuales emergieron tres categorías: Los contextos para la implantación del Consejo Local de Salud; Formación del Consejo Local de Salud ante situaciones del cotidiano de la comunidad: necesidades de salud, participación y renovación; Dificultades afrontadas en el proceso de organización del Consejo Local de Salud. Resultados: Los problemas locales han sido la causa de la participación y la movilización de la comunidad para la implantación y la formación del Consejo Local de Salud. La organización y el funcionamiento del consejo han involucrado usuarios y equipos de salud en prácticas integradas según las demandas y las necesidades del territorio. La participación comunitaria, el empoderamiento para la ciudadanía y la co-responsabilidad solidaria de las personas llevaron al proceso de planeamiento local de las acciones de salud y el afrontamiento colectivo de las dificultades del cotidiano. Conclusión: Los cambios ocurridos en el territorio de la Estrategia de Salud Familiar con la implantación y la formación del Consejo Local de Salud han evidenciado la potencialidad de ese dispositivo de participación social.

Descriptores: Planificación en Salud; Planificación Participativa; Estrategia de Salud Familiar; Consejos de Salud.

\section{INTRODUÇÃO}

A participação popular e o controle social em saúde, entre os princípios do Sistema Único de Saúde (SUS), são muito importantes do ponto de vista social e político, pois se organizam com a garantia de que a população participará do processo de formulação e controle das políticas públicas de saúde. Nesse contexto, destacam-se a institucionalização de espaços de participação da comunidade no cotidiano do serviço de saúde, por meio da garantia da participação no planejamento do enfrentamento dos problemas priorizados, e a efetivação e avaliação das ações, processo no qual a participação popular deve ser garantida e estimulada(1).

A Constituição Federal de $1988^{(2)}$, garantiu a gestão do SUS como responsabilidade compartilhada pela União, estados e municípios, sendo respeitada a autonomia de cada ente federado e com decisões baseadas em consenso representativo paritário, entre o estado e os cidadãos $^{(3)}$.

O Conselho Nacional de Saúde (CNS), em consonância com os conselhos de estados e municípios, define as diretrizes gerais de elaboração do planejamento para todas as esferas de gestão e estabelece as prioridades nacionais para a atenção à saúde ${ }^{(4)}$. O CNS é o espaço participativo que emite os principais documentos regulamentadores dos Conselhos de Saúde (CS), entre eles: as diretrizes para criação, reformulação, estruturação e funcionamento, conforme a legislação federal( ${ }^{(5)}$.

Os municípios, a partir das necessidades locais, das diretrizes estabelecidas pelos Conselhos Municipais de Saúde (CMS) e das prioridades estaduais e nacionais, elaboram, implementam e avaliam o ciclo do planejamento municipal ${ }^{(4)}$. Em algumas localidades existem os Conselhos Locais de Saúde (CLS), que são vinculados a uma Unidade de Saúde e constituídos por representantes, usuários de sua área de abrangência, trabalhadores do próprio serviço e gestores locais do SUS ${ }^{(5)}$. Os CLS são estimulados pelas equipes da Estratégia Saúde da Família (ESF) e objetivam uma governança participativa da comunidade no enfrentamento de seus problemas locais. As dificuldades para o funcionamento estão relacionadas com a capacitação dos conselheiros e o suporte para a operacionalização das atividades ${ }^{(6)}$. 
A ESF integra à Atenção Primária à Saúde (APS), que representa a principal porta de entrada do SUS, e o centro de comunicação das Redes de Atenção à Saúde (RAS). Ela estabelece a coordenação do cuidado e ordena as ações e serviços disponibilizados para os usuários. Cotidianamente, os vínculos entre as equipes de saúde da família e os usuários são mantidos nas ações executadas. Destacam-se, no planejamento local, a análise situacional de saúde, a priorização de riscos e vulnerabilidades e a mobilização comunitária para melhoria da qualidade de vida(7,8).

Na perspectiva de gestão em saúde local e participativa no cenário da ESF, o planejamento pode ser utilizado como um instrumento de gestão no envolvimento da equipe e da comunidade. A união de pessoas envolvidas na deliberação participativa das ações é eficaz na busca de soluções para os problemas que surgem no cotidiano dos serviços de saúde ${ }^{(9)}$. Torna-se necessário o investimento em processos que permitam a adoção de medidas efetivas. Assim, é possível ampliar as possibilidades de intervenção sobre situações consideradas inadequadas, como a redução das desigualdades identificadas pela gestão em relação às condições de vida e saúde do cidadão ${ }^{(10)}$.

O controle social pleno requisita a ampliação de iniciativas de informação, comunicação e participação comunitária na resolução das demandas e necessidades ${ }^{(8)}$. O CLS se configura como espaço menos burocratizado, e pode ser considerado uma prática de cidadania, com potencial gerador de mudanças sociais e melhoria das condições de vida da comunidade ${ }^{(11)}$. Em consonância com a Política Nacional de Promoção da Saúde, a ampliação da participação da população com representatividade coletiva no território potencializa a efetividade das ações, sem eximir a responsabilidade do Estado brasileiro. As iniciativas em rede, de modo intersetorial e participativo, favorecem a autonomia dos atores locais para planejar estratégias de enfrentamento cotidiano e atuar na transformação da realidade social ${ }^{(12)}$.

Neste estudo, utiliza-se, para análise dos dados, o método hermenêutico-dialético, que pressupõe uma investigação compreensiva e dialética, com criticidade atitudinal no contexto de pesquisa. Para tanto, a dialética permite um olhar sobre os distintos significados e sentidos, em seus múltiplos interesses ou posições de contexto. O reconhecimento da linguagem como expressão de semelhanças e diferenças na determinação social e histórica é a compreensão de que nada se constrói fora desse processo ${ }^{(13)}$. Nesse contexto, torna-se relevante expor experiências de gestão local que tenham efetivado movimentos de resolução de problemas para melhoria da saúde e qualidade de vida da população. Assim, o estudo tem por objetivo descrever o processo de implantação do Conselho Local de Saúde, sua formação e as dificuldades enfrentadas, por meio da visão dos conselheiros, com ênfase na participação social no território da Estratégia Saúde da Família.

\section{MÉTODOS}

Este estudo é de natureza qualitativa ${ }^{(14)}$, com abordagem crítico-reflexiva cuja coleta de dados ocorreu no período de fevereiro a julho de 2016. O cenário do estudo se situa na área de abrangência de uma unidade de saúde da ESF no município de Milagres, localizado no sul do estado do Ceará, Brasil. A cobertura da atenção básica é de $100 \%$, com 13 equipes de saúde da família.

A comunidade escolhida para a pesquisa se localiza em zona rural, com o único CLS do município em funcionamento. Nele, a equipe de saúde vinculada ao território é composta por agentes comunitários de saúde (ACS), enfermeira, médico, cirurgião-dentista, técnico de enfermagem, técnico de saúde bucal, motorista, atendente de farmácia, atendente de recepção e duas auxiliares de serviços gerais. O número de famílias cadastradas é de 627 e a população adstrita na ESF-I é de 1.936 pessoas. O CLS tem composição não paritária, formada por 26 conselheiros, com 18 usuários (69\%), em sua maioria representantes de associações comunitárias, igreja, escola e conselho tutelar, além de oito trabalhadores de saúde (31\%), compostos por um cirurgião-dentista e uma enfermeira, cinco ACS e uma técnica de enfermagem ${ }^{(15)}$.

Para a seleção dos participantes, adotaram-se os seguintes critérios de inclusão: ser usuário ou trabalhador da saúde integrante da equipe de saúde da família do território em estudo e membro do CLS. Dos possíveis participantes, quatro não atenderam aos critérios de inclusão. Entre os usuários, dois não puderam participar por estarem em outras atividades no momento da coleta e na equipe de saúde, a técnica de enfermagem, por estar em outra atividade, e a enfermeira da equipe, por ser pesquisadora principal do estudo. Assim, a amostra constou de 22 participantes, membros do CLS, que receberam o convite para fazer parte do estudo após tomarem conhecimento dos objetivos deste e da relevância de sua participação.

Utilizaram-se as técnicas de observação sistemática ${ }^{(16)}$, levantamento documental ${ }^{(17)}$, entrevista semiestruturada ${ }^{(14)}$ e grupo focal ${ }^{(14)}$. O planejamento e a organização se pautaram pela utilização de roteiros e temário, com o objetivo de abordar múltiplas possibilidades de participação dos integrantes do estudo e as informações destes em relação à implantação e funcionamento do CLS. 
Utilizou-se o diário de campo para o registro das informações e anotações das impressões do pesquisador ${ }^{(16)}$. Neste estudo, pautaram-se como pontos de observação: organização do CLS, planejamento e desenvolvimento de atividades, integração da equipe de saúde com a comunidade e resolução integrada e corresponsável dos problemas. Observaram-se dez reuniões do CLS e eventos na comunidade. Coletaram-se informações documentais na unidade de saúde e no CLS, além de nas atas das reuniões ordinárias e extraordinárias. Para a presente pesquisa, os dados, do período de outubro de 2013 a junho de 2016, são sobre a implantação do CLS, composição, funcionamento, representatividade e mobilização social.

Neste estudo, aplicou-se o grupo focal em três sessões: uma com trabalhadores de saúde e duas com usuários. As sessões ocorreram na unidade de saúde da família e na sede da associação de agricultores. A condução dos grupos focais pelos pesquisadores se norteou por meio da temática em questão. Inicialmente, aplicou-se a entrevista semiestruturada, que continha as questões relacionadas à identificação dos participantes (sexo, idade e escolaridade) e de atuação profissional (ocupação, categoria profissional e tempo de atuação na ESF, no caso de trabalhadores da saúde).

Em continuidade da sessão, utilizou-se uma imagem com bonecos coloridos com mãos dadas, representando a diversidade do contexto social, e dispararam-se as discussões com momento reflexivo. As questões temáticas se estabeleciam em sequência, com assuntos sobre: o processo de implantação do CLS, significados do processo para os participantes e os resultados do CLS na vida cotidiana da comunidade, a partir de sua formação e dificuldades enfrentadas.

Salienta-se que todos os 22 integrantes do CLS participaram da discussão do tema, da organização e estruturação do trabalho de campo e da construção do roteiro de questões. Realizou-se o registro dos dados empíricos pela gravação das falas de cada grupo. Cada sessão durou em torno de 45 a 60 minutos. Em consonância com os pressupostos da técnica grupo focal ${ }^{(14)}$, a moderadora conduziu os momentos de apresentação, reflexão e discussão, com a indicação da atividade e a promoção do debate entre os participantes. O observador realizou as anotações relacionadas à interação do grupo.

A etapa da análise dos dados se iniciou pelas transcrições das gravações, seguida por uma leitura exaustiva do material transcrito. E, assim, avançou-se com a análise, concretizada por um movimento articulado entre as fontes empíricas e teóricas, peculiar do método hermenêutico-dialético ${ }^{(14)}$. O entrelaçamento entre teoria e prática gerou três categorias de análise: Contextualidades na implantação do Conselho Local de Saúde; Formação do Conselho Local de Saúde frente às situações cotidianas da comunidade: necessidades de saúde, participação e renovação; Dificuldades enfrentadas na organização do Conselho Local de Saúde.

O estudo condiz com os preceitos éticos envolvendo seres humanos, estando de acordo com a Resolução $\mathrm{n}$. $^{\circ}$ 466/2012 do Conselho Nacional de Saúde ${ }^{(18)}$. A pesquisa recebeu aprovação do Comitê de Ética em Pesquisa da Universidade Regional do Cariri (CEP/URCA), sob Parecer n. ${ }^{\circ}$ 953.830. Os participantes assinaram o Termo de Consentimento Livre e Esclarecido. Para manter o anonimato, denominaram-se Grupo focal 1, 2 e 3 para representar a técnica e sessão; aos participantes, atribuíram-se a nomenclatura dos grupos de usuários e trabalhadores de saúde e a numeração 1 a 16 e 1 a 6 , respectivamente. As falas em destaque neste enfoque são aquelas mais significativas para os temas em questão, as demais estão no relatório da pesquisa e sob a guarda dos pesquisadores.

\section{RESULTADOS E DISCUSSÃO}

Neste espaço serão apresentados os dados de identificação dos participantes do estudo e, em seguida, as categorias de análise que emergiram do estudo.

\section{Dados de identificação dos participantes}

O CLS é representado por usuários e trabalhadores da equipe da ESF. A composição do grupo amostral representado pelos usuários teve 16 participantes, quatro homens e 12 mulheres, com idades entre 23 e 65 anos, com média de 37 anos.

Quanto à escolaridade, dois possuíam o ensino fundamental, 12 o ensino médio e dois tinham nível superior. Sobre a ocupação, sete exerciam atividades do lar, dois eram comerciantes, dois eram artesãos e, ainda, de modo unitário, agricultor, autônomo, professor e conselheiro tutelar. Apenas um participante estava aposentado.

Do grupo representado pelos trabalhadores da saúde, seis pessoas participaram: o cirurgião-dentista e cinco ACS, sendo o grupo constituído por três homens e três mulheres. Tinham idade entre 32 e 65 anos, com média aproximada de 42 anos. Quanto ao tempo de atuação na ESF, os profissionais apresentaram tempo mínimo de seis anos e máximo de 25 anos. Em relação ao grau de escolaridade, dois tinham nível superior e quatro possuíam ensino médio. 


\section{Contextualidades na implantação do Conselho Local de Saúde}

Vivenciar o SUS e sua identidade reafirma a busca por seus princípios por meio da luta e integração institucional, e uma delas é a implementação dos CLS. Nesta categoria, a contextualização histórica da implantação do CLS se expressa nas narrativas e informações sobre os eventos institucionais que se transversalizaram no processo. Em destaque, as conferências municipais de saúde, o Programa Nacional de Melhoria do Acesso e da Qualidade da Atenção Básica (PMAQ-AB) ${ }^{(19)}$ e a motivação por parte da equipe da ESF.

A 14 ${ }^{\text {a }}$ Conferência Municipal de Saúde, em 2011, com o tema "Todos usam o SUS! SUS na Seguridade Social, Política Pública e Patrimônio do povo brasileiro" disparou a necessidade da representação comunitária no evento ${ }^{(20)}$. A motivação da equipe de saúde teve o incentivo da gestão municipal a partir de 2011, com a realização das préconferências locais de saúde nos territórios do município. As narrativas a seguir expressam a participação das pessoas da comunidade e o impulso ao processo de participação comunitária na ESF:

"Eu fui convidado por conta da Pré-Conferência da Saúde no Sítio [refere nome do Sítio] e também por conta de ter só uma conselheira lá. Como a gente costuma dizer, na parte de cima do [refere nome da área], tem. Na parte de baixo, e lá em cima não teve, fica sobrecarregado para apenas uma conselheira, aí fui convidado e estou participando e atuando". (Grupo Focal 3 - Usuário 02)

A fala anterior narra como se deu o caminho de envolvimento dos usuários no controle social, bem como a motivação necessária. O processo motivacional é uma ferramenta que adquire um valor social para quem integra as ações de planejamento e avaliação. Com a participação estimulada pelo serviço de saúde, garante-se a eficiência e a eficácia da gestão pública(21).

Com o intuito de efetivar o interesse da comunidade nas questões de saúde, as pré-conferências locais despertaram sentimentos de pertencimento ao firmar pontes de comunicação que aproximaram as pessoas do território e deu origem à vontade de participar, pelo que está demonstrado na fala a seguir:

"Eu entrei participando de uma reunião [Pré-Conferência local de Saúde], lá no clube do amigo [refere nome do amigo], quando nossa colega enfermeira [refere nome] lançou o convite para quem quisesse fazer parte; eu me prontifiquei a fazer parte, eu fui analisando, pensando e vendo que era um movimento bom, sério e construtivo e quero permanecer até o dia que Deus quiser". (Grupo Focal 2 - Usuário 01)

"Eu fui convidada pelo ACS [Refere nome do ACS], desde então me senti motivada, comecei a entrar nessa luta; desde então me sinto muito gratificada e orgulhosa do serviço que a gente realiza na nossa comunidade e estamos aí dando exemplo para várias comunidades". (Grupo Focal 2 - Usuário 04)

Foi pertinente a união entre profissionais da ESF e usuários em iniciativas que instigaram a construção da autonomia cidadã. $O$ vínculo entre as pessoas expandiu o alcance das resoluções dos problemas da população no CLS, com ampliação da confiança e empoderamento entre os conselheiros ${ }^{(5)}$.

A integração entre profissionais e usuários tão potente em nível local pode ser exemplo para as conferências municipais de saúde. Contudo os formatos das conferências podem ser repensados, uma vez que podem distanciar a população, pois esta apresenta dificuldade para compreender linguagens complexas e deliberações que fogem do seu cotidiano ${ }^{(22,23)}$.

O incentivo e planejamento para consolidação do CLS contou com as ferramentas avaliativas do SUS, principalmente a mobilização comunitária. Em seus módulos avaliativos, o PMAQ-AB esteve atento à participação social. Essa etapa despertou na equipe da ESF o interesse pelo estímulo ao planejamento participativo das ações no território:

"Lembro, assim que a enfermeira [Refere nome] viu no PMAQ-AB, chamou a gente primeiro e perguntou se era viável acontecer no [refere nome da unidade da ESF], e nós demos todo apoio, convidamos as pessoas, pediu para gente repassar para toda a comunidade, convidou as pessoas que se interessavam de livre e espontânea vontade a participar para ajudar mais no ingressar das melhorias da comunidade, pedindo a participação e a coparticipação dos usuários". (Grupo Focal 1 - Trabalhador de saúde 04)

"Nos reunimos com o PMAQ, nos reunimos com a comunidade." (Grupo Focal 1 - Trabalhador de saúde 03)

Para a organização do CLS, resgatou-se o processo operacional do Programa de Melhoria do Acesso e Qualidade (PMAQ) ao avaliar a infraestrutura dos serviços de $A B S$ e o processo de trabalho das equipes e a satisfação dos usuários $^{(19)}$. O PMAQ-AB tem sido um importante agente de mudanças a partir da autoavaliação da equipe de saúde, com potencial para a melhoria da qualidade dos serviços, dos processos de trabalho e ações no território ${ }^{(24)}$. 


\section{Formação do Conselho Local de Saúde frente às situações cotidianas da comunidade: necessidades de saúde, participação e renovação}

Nesta categoria, apresentam-se as ações para organização do CLS que se organizou pelas mãos solidárias da comunidade. Com a abertura para participar da resolução dos problemas, tornou efetiva as ações de Promoção da Saúde no território. A renovação do SUS aconteceu pela mobilização dos usuários e trabalhadores de saúde em busca da transformação social.

A organização do CLS teve como parâmetro a legislação que regulamenta o Conselho Municipal de Saúde $(\mathrm{CMS})^{(25)}$. Entretanto há uma diferença na composição paritária, pois, no CLS, o maior número de membros é representado por usuários $(69 \%, 18)$. Essa composição foi pactuada entre a equipe de saúde e a comunidade, pois representa melhor os segmentos comunitários:

"Como é que a gente organiza o Conselho Local de Saúde: a gente faz igual à do município, pegando todos os segmentos, e a enfermeira [refere nome da Enfermeira] rapidamente organizou o conselho. Surgiu assim: nos reunimos em equipe e convocamos a comunidade, escolhendo segmento de cada área, e formamos $o$ conselho". (Grupo Focal 1 - Trabalhador de saúde 05)

"Houve uma reunião lá no [refere nome do território da pesquisa], e lá nos falaram se a gente ia participar desse Conselho, cada um representando seu segmento, não foi assim? Foi, e a gente aceitou, dando início ao Conselho; eu lembro que foi isso". (Grupo Focal 2 - Usuário 06)

As categorias representativas do CLS foram compostas pela diversidade populacional do território. Os conselheiros se sentiram plenamente identificados por suas condições de vida, trabalho e saúde:

"A gente viu que precisava pegar a participação da comunidade. Estão representados: os jovens, as mulheres, homens, gestantes, mães, idosos, hipertensos, diabéticos, deficientes, agricultores, comerciantes, representantes de igrejas, do sindicato de agricultores e escolas locais". (Grupo Focal 1 -Trabalhador de saúde 01)

"E eu, representante da agricultura, eu era o agricultor; [Refere nome] representou o comerciante". (Grupo Focal 2 - Usuário 02)

"A primeira reunião foi na Associação Comunitária, que eu fiquei como [representante] jovem e [refere nome] ficou como um [representante] do sindicato". (Grupo Focal 2 - Usuário 09)

Foi preciso superar a forma superficial e, quase sempre, burocrática da participação popular em saúde. A população precisava se envolver, tornar-se parte do processo, buscar e sentir seu pertencimento na gestão do SUS. A participação integrada entre comunidade e profissionais da saúde possibilita o sucesso de intervenções comunitárias, uma vez que garante que os problemas detectados sejam efetivamente valorizados pelas comunidades ${ }^{(23)}$.

Torna-se relevante destacar que a motivação pela equipe da ESF tem uma relação direta com o modo de atuação dos profissionais de saúde. Embora as recomendações da gestão municipal e avaliação do PMAQ-AB tenham ocorrido em outras equipes do município, apenas no distrito pesquisado se organizou o CLS. Na prática, o processo de trabalho é potencializado pelas iniciativas dispostas por sujeitos que se afetam pela construção participativa do SUS ${ }^{(26)}$. É importante salientar que nem sempre o cenário é favorável. Apresenta desafios, ruptura de vínculos, cobranças pela comunidade e gestão. As novas práticas de saúde exigem interesse, articulação e zelo para as necessárias medidas voltadas para equilíbrio entre o cuidar e as funções burocráticas ${ }^{(27)}$.

A perspectiva de atuação popular no conselho local do estudo mostrou-se ativa no sentido de trabalhar para um bem comum. Apesar da previsão legal da democracia participativa e do controle social no SUS, a participação cidadã nos conselhos municipais se limita por uma representatividade passiva de seus representantes. Os atributos da motivação institucional para a participação e a proximidade com os problemas podem efetivar a gestão participativa ${ }^{(28)}$.

É preciso reconhecer assimetrias informacionais e cognitivas que podem interferir na qualidade deliberativa. Os diálogos entre os conselheiros são ampliados com a oferta de cursos de capacitação, participação em conferências, implantação da ouvidoria e de comissões temáticas para aprofundar os debates ${ }^{(29)}$.

Sobre o grau de envolvimento dos profissionais, destacam-se os ACS como determinantes para a construção e mobilização dos usuários, resultando em uma participação expressiva nas localidades. Expressa-se que a participação das microáreas contribuiu para a consolidação do CLS:

"A minha comunidade participa em maior número das reuniões por que eu trabalho a importância da participação deles, e eles são mais comprometidos com o movimento, é tanto que eles pedem que as reuniões aconteçam na [refere nome da localidade], porque se doam mais mesmo, como o colega falou". (Grupo Focal 1 - Trabalhador de saúde 02) 
Em sua lida cotidiana, o ACS atua diretamente nas áreas do território. A mediação entre saberes e práticas da equipe de saúde e a comunidade é um processo de múltiplos sentidos e significados. O reconhecimento do conhecimento popular estabelecido nas relações de cuidado, prevenção de doenças e promoção da saúde fortalece a efetividade das ações da ESF, a qual está vinculado( ${ }^{(30)}$.

A composição do conselho apresentou um fluxo de participação e renovação de pessoas. No CLS se permite a mobilidade de conselheiros, seja numa pré-conferência de saúde, seja em uma reunião ordinária:

"Aí nós tivemos a pré-conferência, onde teve uma mudança de participantes, de conselheiros e também aí, dessa mudança, reavivou o conselho, e também, junto com esses novos conselheiros, surgiu muitas demandas". (Grupo Focal 1 -Trabalhador de saúde 06)

"Foi conseguindo mais conselheiros, pessoas para participar, novos conselheiros, para aumentar ainda mais a força do Conselho". (Grupo Focal 1 - Trabalhador de saúde 01)

"Cada vez mais está fortalecendo, novos integrantes estão vindo, acompanhando o trabalho, estamos conseguindo coisas boas tanto para a comunidade como para o próprio trabalho". (Grupo Focal 1 - Trabalhador de saúde 01)

A composição do CLS é decidida durante as pré-conferências distritais, com mandato que dura até a outra Conferência Municipal de Saúde. Quando há a necessidade de renovar os conselheiros, o próprio CLS decide. Assim, a representatividade está assegurada, ao tempo que o apoio pode ser frágil em contextos de apatia participativa $\mathrm{e}$ isolamento do representante ${ }^{(31)}$.

O olhar crítico para a efetivação do CLS assegura e aperfeiçoa o instrumento de participação por meio do desenvolvimento de estratégias e contribui com indicadores positivos. Consideram-se: a efetivação da autonomia financeira; o incentivo ao fortalecimento das entidades de representação social; a promoção de ações para maior visibilidade dos conselhos de saúde; e a criação de rotina para homologação e divulgação das deliberações ${ }^{(32)}$.

\section{Dificuldades enfrentadas na organização do Conselho Local de Saúde}

Os discursos identificaram dificuldades cotidianas durante a implantação do CLS. No início, houve uma baixa adesão ao movimento de organização comunitária, devido à baixa credibilidade da população. Ao tempo que se dispuseram a funcionar, os conselheiros conseguiram mobilizar a comunidade com iniciativas de solidariedade e a persistência das ações, como expressam as narrativas:

"A gente acha que foi complicado chegar até aqui, passamos por dificuldades. Para a gente constituir este conselho houve algumas dificuldades, como no dia da gente se reunir. A gente marcava reunião e o pessoal às vezes vinha, às vezes não vinha, sempre sem aquela credibilidade, não acreditava no conselho, meio desanimado, mas a gente ativou a semente e continuando assim mesmo, até [que] foi melhorando e entrando mais gente, e melhorou, até que estamos aqui. Hoje, o conselho é bem maior em atividades, todos com boa vontade de fazer algo". (Grupo Focal 1 - Trabalhador de saúde 06)

"Apesar das dificuldades no decorrer desses anos, muitas coisas já foram realizadas, muitas e muitas campanhas [de doação entre os moradores] foram realizadas, que já tiveram um bom êxito". (Grupo Focal 3 - Usuário 02)

A superação das limitações ocorreu pelo envolvimento em situações difíceis da própria comunidade, a exemplo da campanha para obtenção de uma cadeira de rodas para um usuário. As campanhas solidárias aproximam pessoas em suas atitudes entre si, pela escuta dos anseios, necessidades e reivindicações, bem como pelas intervenções corresponsabilizadas e também pelo acompanhamento da gestão pública ${ }^{(33)}$.

Nesse processo de construção identitária do CLS, foi possível consolidar um lugar representativo pelo enfrentamento das demandas internas e externas. À medida que se decorreu o tempo, o processo de mobilização envolveu a participação e proporcionou o amadurecimento no grupo de conselheiros, considerado mais coeso e forte:

"Também acho que é uma coisa muito importante que vem acontecendo no decorrer dessas reuniões, que a gente vem fazendo mensal, pode até ser que não tenha sido mensal toda vida, porque a gente às vezes deixou de fazer uma ou outra". (Grupo Focal 2 - Usuário 06)

"Às vezes, tem algumas coisas que dá algumas dificuldades, mas outras não. Então já participei de várias campanhas, como a da cadeira de rodas, que a gente conseguiu, a gente andou lá no [refere nome da comunidade], eu andei junto com a outra conselheira, na época só era eu e ela, a gente andou o [refere nome da comunidade], depois eu andei na cidade, também junto com os outros conselheiros". (Grupo Focal 3 - Usuário 03) 
Com a iniciativa do CLS, apresentou-se uma possibilidade para consolidar a atenção e o planejamento estratégico em saúde ${ }^{(5-7)}$. Na perspectiva de fortalecer o SUS, o CLS envolveu iniciativas que promoveram a saúde e ampliaram a visibilidade sobre as necessidades sociais. Em seu funcionamento, o CLS se tornou um espaço de diálogo, construção do conhecimento e elaboração de ações resolutivas para o bem-estar das pessoas. Em consonância com a Política Nacional de Promoção da Saúde, efetivou o planejamento em saúde com atributos da justiça social, democracia e cidadania ${ }^{(34)}$.

A limitação deste estudo circunda a sua proposição focal, por se tratar de uma experiência singular vivenciada localmente. Sugere-se, para novos estudos, a análise ampliada para outros aspectos, como impactos assistenciais na gestão do SUS.

\section{CONSIDERAÇÕES FINAIS}

A implantação do CLS, assim como a formação representativa, se estabeleceu a partir do envolvimento comunitário com a situação local de saúde e o estimulo da equipe da ESF no território. A representatividade dos usuários foi múltipla e coincidiu com a diversidade dos atores sociais e suas relações cotidianas.

A motivação pela equipe da ESF foi fundamentada para efetivar o processo de participação social. Destaca-se o envolvimento com questões locais e atitudes solidárias, que aproximaram as pessoas na transformação da sua realidade. O controle social potencializa as ações de saúde em seu planejamento, gestão e avaliação.

\section{CONFLITOS DE INTERESSE}

Os autores expressam que não existem conflitos de interesses.

\section{AGRADECIMENTOS}

Aos usuários e equipes de saúde do Sistema Único de Saúde (SUS) de Milagres, Ceará.

\section{CONTRIBUIÇÕES}

Leilany Dantas Varela, Rogério Sampaio de Oliveira e Antônio Germane Alves Pinto contribuíram com a elaboração e delineamento do estudo; a aquisição, análise e interpretação de dados; e a redação e/ou revisão do manuscrito. Rauana dos Santos Faustino, Consuelo Helena Aires de Freitas contribuíram com a redação e/ou revisão do manuscrito. Yana Paula Coêlho Correia Sampaio, Evanira Rodrigues Maia e Maria do Socorro Vieira Lopes contribuíram com a aquisição, análise e interpretação de dados; e a redação e/ou revisão do manuscrito.

\section{FONTES DE FINANCIAMENTO}

Ministério da Saúde. Fundação Oswaldo Cruz (FIOCRUZ). Rede Nordeste de Formação em Saúde da Família (RENASF).

Estudo baseado na dissertação: Conselho local de saúde no território da estratégia saúde da família: participação, envolvimento e solidariedade comunitária. Dissertação (Mestrado Profissional em Saúde da Família - MPSF), pertencente a Rede Nordeste de Formação em Saúde da Família - RENASF. Universidade Regional do Cariri, Crato, Ceará. 2016. 120p.

\section{REFERÊNCIAS}

1. Ministério da Saúde (BR), Secretaria de Gestão Estratégica e Participativa. A construção do SUS: histórias da Reforma Sanitária e do Processo Participativo, Secretaria de Gestão Estratégica e Participativa. Brasília: Ministério da Saúde; 2006.

2. Senado Federal (BR). [Constituição (1988)]. Constituição da República Federativa do Brasil 1988 [Internet]. Brasília: Senado Federal; 2016 [acesso em 2020 Mar 27]. Disponível em: https://www2.senado.leg.br/bdsf/ bitstream/handle/id/518231/CF88_Livro_EC91_2016.pdf

3. Arcari JM, Barros AMA, Rosa RS, Marchi R, Martins AB. Perfil do gestor e práticas de gestão municipal no 
Sistema Único de Saúde (SUS) de acordo com porte populacional nos municípios do estado do Rio Grande do Sul. Ciênc Saúde Colet [Internet]. 2020 [acesso em 2020 Mar 27];25(2). Disponível em: https://www. scielosp.org/article/csc/2020.v25n2/407-420/

4. Ministério da Saúde (BR). Manual de planejamento no SUS, Ministério da Saúde, Fundação Oswaldo Cruz [Internet]. Brasília: Ministério da Saúde; 2016 [acesso em 2020 Mar 27]. Disponível em: http://bvsms.saude. gov.br/bvs/publicacoes/articulacao_interfederativa_v4_manual_planejamento_atual.pdf

5. Zermiani TC, Freitas RS, Pessali HF, Ditterich RG. A participação dos conselhos locais de saúde na contractualização de metas na atenção primária à saúde: a experiência de Curitiba, PR. Interações (Campo Grande) [Internet]. 2019 [Acesso em 2020 Mar 27];20(4). Disponível em: http://www.scielo.br/scielo. php?script=sci_arttext\&pid=S1518-70122019000401115\&lang=pt

6. Jerome JS. Participatory governance in the context of local health councils: interviews with six local health council presidents in Northeastern Brazil. Saúde Soc São Paulo [Internet]. 2018 [acesso em 2020 Mar 27];27(3). Disponível em: http://www.scielo.br/scielo.php?script=sci_arttext\&pid=S0104$12902018000300740 \&$ lang=pt.

7. Ministério da Saúde (BR). Portaria n. ${ }^{\circ} 2.436$ de 21 de setembro de 2017. Aprova a Política Nacional de Atenção Básica, estabelecendo a revisão de diretrizes para a organização da Atenção Básica, no âmbito do Sistema Único de Saúde (SUS) [Internet]. Brasília: Ministério da Saúde; 2017 [acesso em 2020 Mar 27]. Disponível em: http://bvsms.saude.gov.br/bvs/saudelegis/gm/2017/prt2436_22_09_2017.html

8. Oliveira EM, Felipe EA, Santana AS, Rocha IH, Magnabosco P, Figueiredo MAC. Socio-historical determinants of care in the Family Health Strategy: a user perspective in the rural area. Saúde Soc São Paulo [Internet]. 2015 [acesso em 2016 Ago 12];24(3):901-13. Disponível em: http://www.scielo.br/scielo. php?script=sci_arttext\&pid=S0104-12902015000300901\&lng=en\&nrm=iso

9. Figueiredo IDT, Torres GMC, Cândido JAB, Morais APP, Pinto AGA, Almeida, MI. Planejamento estratégico como ferramenta de gestão local na atenção primária à saúde. Rev Fam Ciclos Vida Saúde Contexto [Internet]. 2020 [acesso em 2020 Mar 18];8(1):27-38. doi: 10.18554/refacs.v8i1.3873

10. Fonseca BMC, Braga AMCB, Dias EC. Planning occupational health interventions in the territory: a participatory experience. Rev Bras Saúde Ocup [Internet]. 2019 [Acesso em 2020 Abr 13];44:e33:1-9. doi: 10.1590/2317-6369000015018

11. Busana JÁ, Heidemann ITSB, Wendhausen ÁLP. Participação popular em um conselho local de saúde: limites e potencialidades. Texto \& Contexto Enferm [Internet]. 2015 [Acesso em 2015 Out 23];24(2):442-9. doi: 10.1590/0104-07072015000702014

12. Pinto MB, Silva KL. Promoção da saúde no território: potências e desafios dos projetos locais. Esc Anna Nery [Internet]. 2019 [acesso em 2020 Jun 25];23(1):e20180282. doi: 10.1590/2177-9465-ean-2018-0282

13. Taquette SR. Análise de dados de pesquisa qualitativa em saúde. Actas: Investigação Qualitativa em Saúde. CIAIQ2016 [Internet]. 2016 [acesso em 2020 jun 25];2:524-33. Disponível em: http://proceedings.ciaiq.org/ index.php/ciaiq2016/article/view/790/777

14. Minayo MCS, Deslande SF, Gomes R. Pesquisa social: teoria, método e criatividade. Petrópolis: Editora Vozes; 2016.

15. Ceará. Documento 1: Livro Ata do Conselho Local de Saúde do Rosário - 2013 a 2016 do Município de Milagres - CE. 2016.

16. Flick U. Introdução à Pesquisa Qualitativa. $3^{\text {a }}$ ed. Porto Alegre: Artmed-Bookman; 2009.

17. Cellard A. A análise documental. In: Poupart J, Deslauriers JP, Groulx LH, Laperriere A, Maye R, Pires A. A pesquisa qualitativa enfoques epistemológicos e metodológicos [Internet]. 3 ed. Petrópoles: Vozes; 2012 [acesso em 2020 Jun 25]. p. 295- 316. Disponível em: file:///C:/Users/mende/Downloads/ANDRE_ CELLARD_-_A_analise_documental._p.pdf

18. Ministério da Saúde (BR). Diretrizes e normas regulamentadoras da pesquisa envolvendo seres humanos: resolução $n^{\circ}$ 466/12, n 112, Seção 1, pág. 59 [Internet]. Brasília: Ministério da Saúde; 2012 [acesso em 2020 Jun 25]. Disponível em: https://conselho.saude.gov.br/resolucoes/2012/Reso466.pdf 
19. Seus TL, Silveira DS, Tomasi E, Thúme E, Facchini LA, Siqueira FV. Structure for the work and composition of Family Health Support Unit teams: national survey - Program for Improving Primary Health Care Access and Quality (PMAQ), 2013*. Epidemiol Serv Saude. 2019;28(3):2018510.

20. Ministério da Saúde (BR). Conselhos de saúde: a responsabilidade do controle social democrático do SUS [Internet]. $2^{a}$ ed. Brasília: Ministério da Saúde; 2013. Disponível em: http://bvsms.saude.gov.br/bvs/ publicacoes/conselhos_saude_responsabilidade_controle_2edicao.pdf

21. Sabioni M, Ferreira MAM, Reis AO. Racionalidades na motivação para a participação cidadã no controle social: uma experiência local brasileira. Cad EBAPE.BR [Internet]. 2018 [acesso em 2020 abr 13];16(1). doi: http://dx.doi.org/10.1590/1679-395155420

22. Ricardi LM, Shimizu HE, Santos LMP. As Conferências Nacionais de Saúde e o processo de planejamento do Ministério da Saúde. Saúde Debate [Internet]. 2017 [acesso em 2020 Abr 01];41(3). doi: 10.1590/010311042017 s312

23. Sousa FAMR, Goulart MJG, Braga AMS, Medeiros CMO, Rego DCM, Vieira FG, et al. Estabelecimento de prioridades em saúde numa comunidade: análise de um percurso. Rev Saúde Pública [Internet]. 2017 [acesso em 2020 Abr 1];51(11). doi: 10.1590/S1518-8787.2017051006460

24. Uchôa SAC, Martiniano CS, Queiroz AAR, Bay OG Jr, Nascimento WG, Albuquerque IV, et al. Inovação e utilidade: avaliação Externa do Programa Nacional de Melhoria do Acesso e da Qualidade da Atenção Básica. Saúde Debate [Internet]. 2018 [acesso em 2020 Abr 1];42(spe1):100-13. doi: 10.1590/010311042018 s 107

25. Presidência da República (BR). Lei n. ${ }^{\circ} 8.142$, de 1990. Dispõe sobre a participação da comunidade na gestão do Sistema Único de Saúde - e sobre as transferências intergovernamentais de recursos financeiros na área da saúde e dá outras providências [Internet]. Brasília: Presidência da República; 1990 [acesso em 2020 Abr 1]. Disponível em: http://www.planalto.gov.br/ccivil_03/leis/L8142.htm

26. Andrade RS, Caldas LBN, Falcão MLP, Goes PSA. Processo de Trabalho em Unidade de Saúde da Família e a Educação Permanente. Trab Educ Saúde [Internet]. 2016 [acesso em 2016 Ago 16];14(2):505-21. Disponível em: https://www.scielo.br/scielo.php?pid=S1981-77462016005002101\&script=sci_abstract\&tlng=pt

27. Santos ROM, Romano VF, Engstrom EM. Vínculo longitudinal na Saúde da Família: construção fundamentada no modelo de atenção, práticas interpessoais e organização dos serviços. Physis [Internet]. 2018 [acesso em 2020 Abr 02];28(2):280206. Disponível em: http://www.scielo.br/pdf/physis/v28n2/01037331-physis-28-02-e280206.pdf

28. Barddal FME, Torres RL. Efetividade da participação cidadã nos conselhos municipais de Curitiba. Rev Bras Gest Urbana [Internet]. 2020 [acesso em 2020 Abr 03];12. Disponível em: http://www.scielo.br/scielo. php?script=sci_arttext\&pid=S217533692020000100203\&lang=pt

29. Bortoli FR, Kovaleski DF. Efetividade da participação de um conselho municipal de saúde na região Sul do Brasil. Saúde Debate [Internet]. 2019 [acesso em 2020 Abr 3];43(123):1168-80. Disponível em: http://www. scielo.br/pdf/sdeb/v43n123/0103-1104-sdeb-43-123-1168.pdf

30. Dantas DSG, Silva MRF, Torres RAM, Oliveira LC, Pinto FJM, Sampaio RMM. Training of community health agents in popular education: involvement in the production of care in the Family Health Strategy. Motri [Internet]. 2018 [acesso em 2020 Abr 13];14(1):157-63. Disponível em: http://www.scielo.mec.pt/pdf/mot/ v14n1/v14n1a21.pdf

31. Bispo JP Jr. Advances and Challenges of Institutionalized Participation in Brazil's Health System. Rev Crít Ciênc Soc [Internet]. 2018 [acesso em 2020 Abr 13]:(117):99-122. Disponível em: http://www.scielo.mec.pt/ $\mathrm{pdf} / \mathrm{rccs} / \mathrm{n} 117 / \mathrm{n} 117 \mathrm{a} 06 . \mathrm{pdf}$

32. Rocha MB, Moreira DC, Bispo JP Jr. Conselho de saúde e efetividade participativa: estudo sobre avaliação de desempenho. Cad Saúde Pública [Internet]. 2020 [acesso em 2020 Abr 03];36(1):00241718. Disponível em: http://www.scielo.br/pdf/csp/v36n1/1678-4464-csp-36-01-e00241718.pdf

33. Miranda AS, Moreira AEMM, Cavalcanti CGCS, Bezerra FM, Oliveira JC, Rezende R. Practical discourses about events, decisions processes and effects of Health municipal conferences in Brazil. Interface (Botucatu) 
[Internet]. 2016 [acesso em 2020 Abr 13];20(58):559-71. Disponível em: http://www.scielo.br/pdf/icse/ v20n58/1807-5762-icse-1807-576220150300.pdf

34. Malta DC, Reis AAC, Jaime PC, Morais OL Neto, Silva MMA, Akerman M. O SUS e a Política Nacional de Promoção da Saúde: perspectiva resultados, avanços e desafios em tempos de crise. Ciênc Saúde Colet [Internet]. 2018 [acesso em 2020 Jun 25];23(6):1799-809. Disponível em: http://www.scielo.br/scielo. php?script=sci_arttext\&pid=S1413-81232018000601799\&Ing=en

\section{Endereço do primeiro autor:}

Leilany Dantas Varela

Secretaria Municipal de Saúde de Milagres

Rua José Miguel de Figueiredo, S/N

Bairro das Missionárias

CEP: 63250-000 - Milagres - CE - Brasil

E-mail: leyla_nurse@yahoo.com.br

\section{Endereço para correspondência:}

Rauana dos Santos Faustino

Universidade Estadual do Ceará

Av. Dr. Silas Munguba, 1700

Bairro: Itaperi

CEP: 60714-903 - Fortaleza - CE - Brasil

E-mail: rauanafaustino21@gmail.com

Como citar: Varela LD, Faustino RS, Freitas CHA, Sampaio YPCC, Oliveira RS, Pinto AGA, et al. Conselho local de saúde: implantação e dificuldades da formação na Estratégia Saúde da Família. Rev Bras Promoç Saúde. 2020;33:10908. 